\title{
23
}

\section{Bio-Sudoku 3}

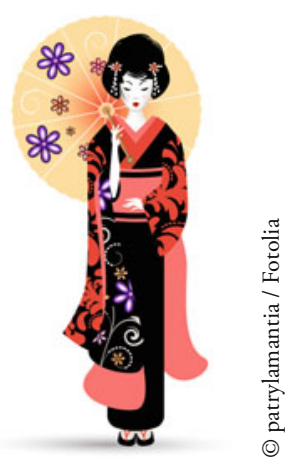

Ein Buchstaben-Sudoku wird wie ein gewöhnliches Sudoku gelöst. Der Unterschied: Statt mit den sonst verwendeten Zahlen von 1 bis 9 wird dieses Rätsel mit folgenden neun Buchstaben ausgefüllt:

$A-P-N-R-E-H-X-Y-K$

\begin{tabular}{|c|r|r|r|r|r|r|r|r|}
\hline & & A & X & H & N & 5 & R & P \\
\hline 7 & & & & P & & & & E \\
\hline P & N & Y & & R & K & & & \\
\hline A & P & & R & E & X & 2 & K & Y \\
\hline Y & H & K & P & 6 & A & & E & X \\
\hline R & E & X & & K & H & & P & N \\
\hline & & 1 & K & X & & E & H & A \\
\hline K & 3 & E & H & Y & P & & X & \\
\hline H & X & & N & & E & & & K \\
\hline
\end{tabular}

Lösung:

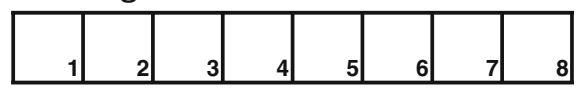

(C) Springer-Verlag Berlin Heidelberg 2016

C. Reinbold, Fetthenne, Moderlieschen, Warzenbeißer,

DOI 10.1007/978-3-662-52817-4_23 